\title{
Sexual and reproductive health services utilization and associated factors among secondary school students in Nekemte town, Ethiopia
}

Wakgari Binu', Taklu Marama², Mulusew Gerbaba ${ }^{3}$ and Melese Sinaga ${ }^{3}$

\begin{abstract}
Background: Despite policy actions and strategic efforts made to promote sexual and reproductive health service uptake of youths in Ethiopia, its utilization remains very low and little information was found on the extent to which school youths utilize available reproductive health services in Nekempt town. This study was aimed to assess utilization of Sexual and Reproduactive Health (SRH) services and its associated factors among secondary school students in Nekemte town, Ethiopia.

Method: A school based cross-sectional study design was conducted from April 18 to 22, 2016. Multistage cluster sampling technique was used to select a total of 768 students who attended secondary schools. Sexual and reproductive health services utilization was measured using one item asking whether they had used either of sexual and reproductive health services components during the last one year or not. The data was entered using EpiData Manager with Entry Client and further analysis was done using SPSS version 21 software. Descriptive statistics, cross tabulations, biviarate and multivariate logistic regression analyses were used. All variables were set by $p$-values less than 0.05 and reported by Adjusted Odds Ratio with its $95 \% \mathrm{Cl}$.
\end{abstract}

Result: Out of the 768 study subjects, 739 participants underwent all the study components giving response rate of 96\%. About 157 (21.2\%) school youths reported that they utilized SRH services. On multivariable logistic regression analysis after adjusting for other variable, discussion with health workers (AOR 3.0, 95\%Cl [1.7-5.2]), previous history of perceived Sexually transmitted infections (STIs) symptoms (AOR 2.6, 95\%Cl [1.2-5.5]), being ever sexually experienced (AOR 5.9, 95\% [3.4-10.2]) and exposure to information from school teachers (AOR 0.36, 95\%Cl [0.2-0. 6]) were found to be independent determinants of sexual and reproductive services utilization among secondary school youths. Inconvenient times, lack of privacy, religion, culture, and parent prohibition were barriers to SRH service uptake cited by the school youths.

Conclusions: The overall utilization of sexual and reproductive services was low among school youths in the town. Discussion with health workers, history of perceived STIs symptoms, sexual experience and information were the association factors of sexual and reproductive service utilization among secondary school youths.

\footnotetext{
*Correspondence: mtaklu2002@gmail.com

${ }^{2}$ Department of Midwifery, College of Health Sciences and Medicine, Wolaita

Sodo University, Wolaita Sodo, Ethiopia

Full list of author information is available at the end of the article
} 


\section{Plain English summary}

Even if policy actions and strategic efforts made to promote sexual and reproductive health service uptake of youths in Ethiopia, few literatures showed its utilization remains very low. So, this study was aimed to assess utilization of Sexual and reproductive Health (SRH) services and its associated factors among secondary school students in Nekemte town, Ethiopia.

Students' utilized as well as utilizing Sexual and reproductive Health services before and during April 18th to 22nd, 2016 are included in the study. Among 12 above grade 9 schools, two government and 2 non-government schools were selected using lottery methods. For this study, a total of 768 students were needed. To have these, students from each grade and sections were randomly selected from their attendance lists. On the day of data collection the randomly selected students were told to remain in their classes. Sexual and Reproductive Health services utilization was measured if the students utilized one of the six given components. To keep data quality first data was entered to EpiData Manager and exported to SPSS version 21 software to have the required output. The result was described in table and figures, and cross tabulated. Bivariate logistic regression model was used to see association between utilization and other factors.

In this study, only 157 (21.2\%) of students reported their utilization of Sexual and Reproduction Health services. Students who discussed with health workers, perceived history of Sexually transmitted infections (STIs) symptoms previously, experienced sex ever and exposed to information from school teachers were found to be better utilized Sexual and Reproductive Health services.

When summarized, the overall utilization of SRH services was low among school youths in the town.

\section{Background}

There were 1.8 billion young people aged 10-24 years among which 1.2 billion youth aged $15-24$ years globally in 2015, accounting for one out of every six people worldwide in which Africa comprises 19\% (above 226 million) of the global youth population [1]. Young people make up the greatest proportion of the population in sub-Saharan Africa, with more than one-third of the population $10-24$ ages [2], and $33.8 \%$ of the total population in Ethiopia is between the age of 10-24 [3].

Since the International Conference on Population and Development Key Informant Interview held in Cairo in 1994, governments have pledged to improve the SRH of adolescents by providing access to comprehensive, appropriate information and education and youth friendly health services. Most regions of the world however, still fall short of these commitments, especially for unmarried young people [4].
Even though the comprehensive knowledge of HIV and other Reproductive Health ( $\mathrm{RH}$ ) problems is increasing around the world, many young people do not have the information or means to protect themselves from these problems [5]. Many health problems are contributed by adolescents and young people worldwide: 8.7 million abortions undergone, $41 \%$ of new HIV infection, high rate of early marriage and STIs, and high proportion of stillbirth and newborn deaths [6].

In Africa, 430,000 young people are infected with HIV per year; 2.6 million young people are living with HIV; teenage pregnancy rates still remain high and maternal mortality is among the leading causes of death for adolescent girls in this region [7]. Studies done in Ethiopia also show that there was $42.1 \%$ sexual risk behavior [8], $19 \%$ of youths reported having had premarital sexual intercourse with the mean age of 16.48 years at the first sexual intercourse [9], self-reported STIs prevalence was $19.5 \%$ [10] and abortion rate was also 65 per 1000 women [11].

Concerning the utilization of SRH services, it is not enough as expected from the efforts tried in Ethiopia. The SRH services utilization has great variation, $21.5 \%$ in Hadya [12] to 96.1\%in Harar [13], that refers different factors are affecting the utilization differently in different part of the country. The SRH services utilization is high in areas where youth friendly services are available and accessible at community level [13]. It is evidenced that high school students were visiting SRH services to receive SRH information, for counseling service, to obtain a condom, for treatment of STI, for postabortion care [14] while others were not using SRH services because of inconvenience service hour, feel fear to be seen by others, too long waiting hours, providers are judgmental and unfriendly, feel embracement at seeking $\mathrm{RH}$ services [15]. Even, the utilizationof SRH services among secondary school students is not well explored in the country and the existing studies do not show enough information about the SRH situation of secondary school students, resulting in the absence of sustainable school based intervention for secondary chool students. So, additional study that assesses the magnitude and factors affecting SRH service utilization is very crucial to improve SRH service utilization of secondary school young people in the study area in the way that reduce morbidities and disabilities related to sexual and reproductive health.

\section{Methods}

Institution based cross-sectional study design was conducted in Nekemte town, East Wallaga zone, Western Ethiopia from April 18th to 22nd, 2016. Nekemte Town is situated $331 \mathrm{~km}$ from Addis Ababa city. The town covers an area of 5480 ha. According to data from 
Central Statistics Agency Branch in the town, the total population of the town is projected to be 97,289 and young people in the town is estimated to be 37,796 $($ male $=19,626$, female $=18,170)$ in 2016 [16].

According to the information from Nekemte Town Education Office, the total number of young people enrolled to secondary school (grade 9-12) in 2015/16 was 11,428 $($ male $=5539$, female $=5867)$ students in seven government secondary schools $9771(85.5 \%)$ and five nonegovernment (two Non-Governmental Organizations (NGO) and three Private) secondary schools 1657(14.5\%). The government schools are free of charge for educational purposes. From the estimated total population of young people, only $30.24 \%$ (28.22\% of male and $32.29 \%$ of female) of young people were attending schools. The data from Nekemte Town Health Office showed that the town has one general hospital, two government health centers, one higher and twelve medium private clinics, twelve NGO health facilities that are serving the society. From these health facilities, one government health centre and two NGO clinics were delivering SRH services and youth friendly services separately which is free of charge.

All secondary school students enrolled in the year 2015/ 2016 in the town were the source population and all the students in randomly selected secondary schools were the study population. Sample size was calculated using single population proportion formula by taking the proportion (p) of SRH services utilization by school youths to be $32 \%$ taken from the study conducted in Bahir Dar Town (19) [17] with the conservative assumptions in order to get enough sample size that would allow the study to look into various aspects of school youths. The assumptions of 95\% confidence level (level of significance, $z_{\alpha}=1.96$ ), $5 \%$ margin of error, design effect of 2.0 and $15 \%$ non-response were used to determine the sample size. Accordingly, the total sample size was 768 .

Concerning Sampling Techniques, Multistage cluster sampling technique was used in order to select a representative sample of students. Four schools (two from government ant two from non-government) were selected randomily. Samples were selected from government and non-government schools proportional to their size of the student population. The total sample was allocated to each grade from grade 9 to 12 proportionate to their student population size; Then four (2 government and 2 non-government) schools were selected using simple random sampling to recruit the allocated subjects for each grade. From each grade, sections were selected randomly and finally the study subjects were selected by using lottery method in SPSS using their attendance lists in the respective schools. On the day of data collection the randomly selected students were told to remain in their classes.

The dependent variable in this study was whether a participant had utilized SRH services within the last
12 months anywhere whether in government or private health institutions. This was measured through the dichotomous response (yes or no). The positive response was further validated with questions on the type of SRH services utilized. This included information and counseling on SRH issues, family planning, voluntary testing and counseling on HIV, abortion care, maternal and child care, testing and treatment of STIs. A positive ("yes") response to any one of these services was regarded as service utilization. The questionnaire was developed by collecting and adopting after customizing into the study context from various literatures [18-20].

The quality of data were assured by translating questionnaires from English to Afan Oromo then back to English by another expert using properly designed and pretested questionnaire. The data was collected by two Diploma Nurses and supervised by 1 BSc Nurse who were trained for two days. The pretest was done on $5 \%$ of the sample size in Gimbi secondary school, a $100 \mathrm{~km}$ Town from Nekemte and some modifications such as skipping pattern and sequence sections in the questionnaire were made. To maintain confidentiality, each participant took a single sparsely arranged seat and the participant put the questionnaire on separate table arranged at corner of the room.

The questionnaires were designed by using Epidata manger and entry-client. Regarding data analysis and management, all returned questionnaires were checked for completeness and consistency manually. Thereafter, data was coded, entered into EPI-data entry client 2.0.8. 56 and exported to Statistical Package for the Social Sciences (SPSS) version 21. Frequencies and percentages were used to summarize descriptive statistics. Bivariate logistic regression analysis was done by entering variables that were found to affect SRH utilization. Variables with the $p$-value of less than or equal to 0.25 were entered into multivariate logistic regression. Those variables statistically significant at p-value less than 0.05 in multivariate logistic regression analysis were found to be taken as statistically significant. Adjusted odds ratio with the confidence level of $95 \%$ was considered to assess the strength of the association between dependent and independent variables.

\section{Some phrases are Operationed as follows: \\ Attitude}

Respondents has favorable attitude if they score equal or above mean score (66.48) of the total 24 attitude questions with 1-5 likert scale points.

\section{Knowledge of SRH services}

First knowledge about the SRH services was assessed by asking participants whether they were aware of SRH service components or not. Then SRH knowledge was assessed 
through 8-item scale on knowledge of SRH service components and the sum of scores ranging from one (minimum) to eight (maximum) for subjects were used in the analysis.

\section{SRH services utilization}

This was measured through the dichotomous response (yes or no) by asking whether a participant had utilized one or more of SRH service components within the last 12 months. The positive response was further validated with questions on the type of SRH services utilized. A positive ("yes") response to any one of these services was regarded as service utilization.

\section{Results}

Out of the total of 768 study participants, 739 of students took part in the survey giving a response rate of $96.0 \%$. Out of these, 349(47.2\%) were males, $665(90.0 \%)$ and $74(10.0 \%)$ falls under the age group of $15-19$ and 20-24 years respectively with the mean age of $17.3(\mathrm{SD}= \pm 1.7)$; $25(3.4 \%)$ and 136(18.4\%) were single and in relationship respectively. Majority of them 925(97.4\%) were Oromo by ethnic group, and protestant 525(55.5\%) followers. Regarding their current educational status, h $82.9 \%$ and $17.1 \%$ of them were attending government and private schools respectively. The result also shows that the fathers $666(91.1 \%)$ and mothers $573(77.5 \%)$ of respondents were formally educated and $291(39.4 \%)$ of fathers and $220(29.8 \%)$ of mothers were employed. Majority of the students $486(65.8 \%)$ were living with their family (Table 1).

\section{Knowledge, attitudes towards SRH services and sexual practices}

Three hundred fifteen (42.6\%) and $30(4.1 \%)$ of the respondents know at least one and eight SRH service components respectively. Six hundred eighty six of participants have an information on SRH services and $564(76.3 \%)$ of participants were aware of at least one health facility where SRH services could be delivered. Government health facilities, private health facilities, NGO health facilities and traditional facilities were SRH services delivery points as cited by $509(68.9 \%), 286(38$. $7 \%), 187(25.3 \%)$ and $50(6.8 \%)$ of the respondents respectively. Majority of the respondents $(72.7 \%)$ have involved in the available school clubs and 400 (54.3\%) had discussed on SRH issues with friends followed by health workers 163 (22.1\%). 387(52.4\%) of respondents had favorable attitude towards the SRH services. A total of 140 (18.9\%) of respondents had ever experienced sexual intercourse and 101 (13.7\%) of respondents had sexual contact within the last 12 months. The mean age at first sexual contact of respondents was 15.14 $(\mathrm{SD}= \pm 2.98)$ years. This study also showed that $70(69.3 \%)$ of the sexually active respondents were male and $16(15.8 \%)$ of them had more than one sexual partners (Table 2).
Table 1 Socio-demographic, community and family characteristics of secondary school students in Nekemte Town, Ethiopia, April 18-22, 2016

\begin{tabular}{|c|c|c|c|}
\hline \multicolumn{2}{|c|}{ Socio-demographic characteristics } & \multirow{2}{*}{$\begin{array}{l}\text { Frequencies } \\
665\end{array}$} & \multirow{2}{*}{$\begin{array}{l}\text { Percentage } \\
90.0\end{array}$} \\
\hline Age & $15-19$ & & \\
\hline & $20-24$ & 74 & 10.0 \\
\hline \multirow[t]{2}{*}{ Sex } & Male & 349 & 47.2 \\
\hline & Female & 390 & 52.8 \\
\hline \multirow[t]{3}{*}{ Marital status } & Married & 25 & 3.4 \\
\hline & In a love relationship & 136 & 18.4 \\
\hline & Single & 578 & 76.0 \\
\hline \multirow[t]{2}{*}{ Ethnicity } & Oromo & 719 & 97.3 \\
\hline & Others & 20 & 2.7 \\
\hline \multirow[t]{5}{*}{ Religion } & Protestant & 405 & 54.8 \\
\hline & Orthodox & 155 & 21.0 \\
\hline & Wakefata & 140 & 18.9 \\
\hline & Muslim & 28 & 3.8 \\
\hline & Others $^{* * *}$ & 11 & 1.4 \\
\hline \multirow[t]{4}{*}{ Educational status } & Grade 9 & 297 & 40.2 \\
\hline & Grade 10 & 173 & 23.4 \\
\hline & Grade 11 & 134 & 18.1 \\
\hline & Grade 12 & 135 & 18.3 \\
\hline \multirow[t]{2}{*}{ School type } & Government & 613 & 82.9 \\
\hline & Private & 126 & 17.1 \\
\hline \multirow[t]{3}{*}{ Pocket money in ETB } & No money & 224 & 30.3 \\
\hline & $1-500$ & 450 & 60.9 \\
\hline & $>500$ & 65 & 8.8 \\
\hline \multirow[t]{2}{*}{ Mother's education } & No formal education & 166 & 22.5 \\
\hline & Formal education & 573 & 77.5 \\
\hline \multirow[t]{2}{*}{ Father's education } & No formal education & 73 & 9.9 \\
\hline & Formal education & 666 & 91.1 \\
\hline \multirow[t]{2}{*}{ Mother's occupation } & Unemployed & 519 & 70.2 \\
\hline & Employed & 220 & 29.8 \\
\hline \multirow[t]{2}{*}{ Father's occupation } & Unemployed & 448 & 60.6 \\
\hline & Employed & 291 & 39.4 \\
\hline \multirow[t]{2}{*}{ Living arrangement } & Living with family & 486 & 65.8 \\
\hline & Not living with family & 253 & 34.1 \\
\hline \multirow[t]{2}{*}{ Family residence } & Urban & 534 & 72.3 \\
\hline & Rural & 205 & 27.7 \\
\hline
\end{tabular}

Others $=$ Amhara, Guraghe, Tigrie Others $^{* * *}=$ Adventist, Catholic, Jhoba

Respondents answered media 333(45.1\%), teachers 305(41. $3 \%$ ), health workers $271(36.7 \%)$, friends $198(26.8 \%)$ as their potential sources of information for SRH services (Fig. 1).

\section{Utilization of SRH services}

This study result showed that 157(21.2\%) of overall study subjects had received at least one component of 
Table 2 Knowledge, Attitudes towards SRH services and Sexual practices among secondary school youths in Nekemte Town, 2016

\begin{tabular}{|c|c|c|c|}
\hline \multicolumn{2}{|l|}{ SRH services and sexual related } & \multirow{2}{*}{$\begin{array}{l}\text { Frequencies } \\
686\end{array}$} & \multirow{2}{*}{$\frac{\text { Percentage }}{92.8}$} \\
\hline Awareness of SRH services $(n=739)$ & Yes & & \\
\hline & No & 53 & 7.2 \\
\hline \multirow[t]{2}{*}{ Awareness of Health facilities $(n=687)$} & Yes & 564 & 76.3 \\
\hline & No & 123 & 16.6 \\
\hline \multirow[t]{8}{*}{ Source of information on SRH services (Multiple Response) } & Parent talk & 116 & 12.2 \\
\hline & Friends & 198 & 26.8 \\
\hline & Relatives & 60 & 8.1 \\
\hline & Health workers & 271 & 36.7 \\
\hline & School teachers & 305 & 41.3 \\
\hline & School clubs & 149 & 20.2 \\
\hline & Medias & 333 & 45.1 \\
\hline & Printed materials & 154 & 20.8 \\
\hline \multirow[t]{2}{*}{ Participated in school clubs } & Yes & 537 & 72.7 \\
\hline & No & 202 & 27.3 \\
\hline \multirow[t]{6}{*}{ Discussion on SRH topics with (Multiple Response) } & Mother & 88 & 11.3 \\
\hline & Father & 32 & 4.3 \\
\hline & Brother/sister & 66 & 9 \\
\hline & Friends & 400 & 54.3 \\
\hline & Health workers & 163 & 22.1 \\
\hline & Relatives & 34 & 4.6 \\
\hline \multirow[t]{4}{*}{ Awareness of health facilities where to get SRH services (Multiple Response) } & Government & 509 & 68.9 \\
\hline & Private & 286 & 37.8 \\
\hline & Non-government & 187 & 25.3 \\
\hline & Traditional & 50 & 6.8 \\
\hline \multirow[t]{2}{*}{ Sexually ever experienced } & Yes & 140 & 18.9 \\
\hline & No & 599 & 81.1 \\
\hline \multirow[t]{2}{*}{ Currently sexually active } & Yes & 101 & 13.7 \\
\hline & No & 638 & 86.3 \\
\hline \multirow[t]{2}{*}{ Currently sexually active } & Male & 70 & 69.3 \\
\hline & Female & 31 & 29.7 \\
\hline \multirow[t]{2}{*}{ Partners for sexually actives } & Only one & 85 & 84.2 \\
\hline & More than one & 16 & 15.8 \\
\hline \multirow[t]{2}{*}{ Attitude towards SRH services use $(n=737)$} & Unfavorable & 350 & 47.5 \\
\hline & Favorable & 387 & 52.5 \\
\hline
\end{tabular}

the SRH services in the last twelve months. Majority of the participants $116(54.8 \%)$ reported government health facilities from where they received SRH services followed by NGO health facilities $46(29.3 \%$ ) (Table 3 ).

The most frequently utilized SRH services was Volunteer Test and Counseling 93(59.2\%) followed by information and counseling on SRH issues 80(51\%) and condom service $46(29.3 \%)$. The result also showed $27(26.7)$ of the sexually active respondents had utilized family planning methods in the last twelve month (Fig. 2).
In this study, 582(78.8\%) of the study participants did not use SRH services in the last twelve months. The most frequently reported reasons for not utilizing SRH services, are not encountering any problem $249(42.8 \%)$ ,and believing that the services were not necessary 135 (23.2\%) majorly (Fig. 3).

\section{Factors associated with utilization of SRH services}

During bivariate analysis, being in 20-24 age (COR 2.36, 95\% CI [1.34 to 4.16]), being married (COR 2.69, 95\%CI [1.14 to 6.34]), history STIs (COR 4.41, 95\%CI [2.46 to 7.91]), 


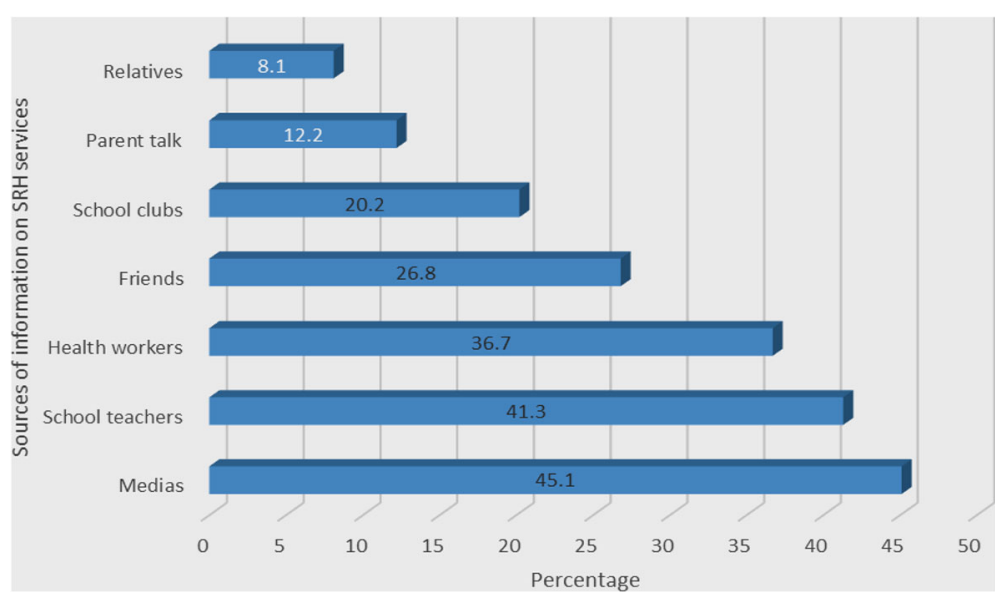

Fig. 1 Sources of information on SRH services for secondary school youths in Nekemte Town, April 18-22, 2016

having ever sexual contact (COR 7.51, 95\%CI [4.87 to 11.6]), and having favorable attitude towards SRH services (COR 1. 46, $95 \% \mathrm{CI}$ [1.01 to 2.13]), heard SRH information from school teachers (COR 0.4, 95\%CI [0.27, 0.59]) discussing on $\mathrm{SRH}$ issues with friends (COR 0.46, 95\%CI [0.3, 0.72]), discussing on SRH issues with health care workers (COR 2.78, $95 \% \mathrm{CI}[1.8,4.3])$ and attending non-government schools (COR 0.46, 95\%CI [0.27-0.79]) were found to be associated with SRH services utilization (Table 4).
After controlling the effects of confounding, multivariate logistic regression analysis showed that the likelihood of SRH service utilization among secondary school was about 3 times (AOR $=3,95 \% \mathrm{CI}$ [1.72 to 5.24]) higher among respondents who discussed SRH issues with health workers than their counterparts. Students who had heard SRH issues from their school teachers were $64 \%(\mathrm{AOR}=0.36,95 \% \mathrm{CI}[0.21$ to 0.61$])$ less likely to utilize SRHS than those who had not heard SRH related

Table 3 SRH service utilization and reasons don't use the services by secondary school youths in Nekemte Town, April 18-22, 2016

\begin{tabular}{|c|c|c|c|}
\hline Characteristics & & Frequency & Percentage \\
\hline \multirow[t]{2}{*}{ Utilized at least one SRH service $(n=739)$} & No & 582 & 78.8 \\
\hline & Yes & 157 & 21.2 \\
\hline \multicolumn{4}{|l|}{ SRH services utilized in the last 12 months $(n=157)$} \\
\hline Information and counseling on SRH issues & & 80 & 51 \\
\hline Family planning services & & 34 & 21.7 \\
\hline Pregnancy test & & 15 & 9.6 \\
\hline Pregnancy care & & 7 & 4.5 \\
\hline Abortion care services & & 5 & 3.2 \\
\hline Condom services & & 46 & 29.3 \\
\hline STIs treatment services & & 28 & 17.8 \\
\hline Voluntary testing and counseling for HIV & & 93 & 59.2 \\
\hline \multirow[t]{2}{*}{ Sexually actives utilized FP methods $(n=101)$} & Yes & 27 & 26.7 \\
\hline & No & 74 & 74.3 \\
\hline \multicolumn{4}{|l|}{ Facilities where SRH services received $(n=157)$} \\
\hline Government & & 86 & 54.8 \\
\hline Private & & 35 & 22.3 \\
\hline Non-government & & 46 & 29.3 \\
\hline Traditional & & 6 & 3.8 \\
\hline
\end{tabular}

N.B. System missed values were excluded from analysis, some observations may exceed $100 \%$ due to multiple options and others may be less than $100 \%$ due to missed values 


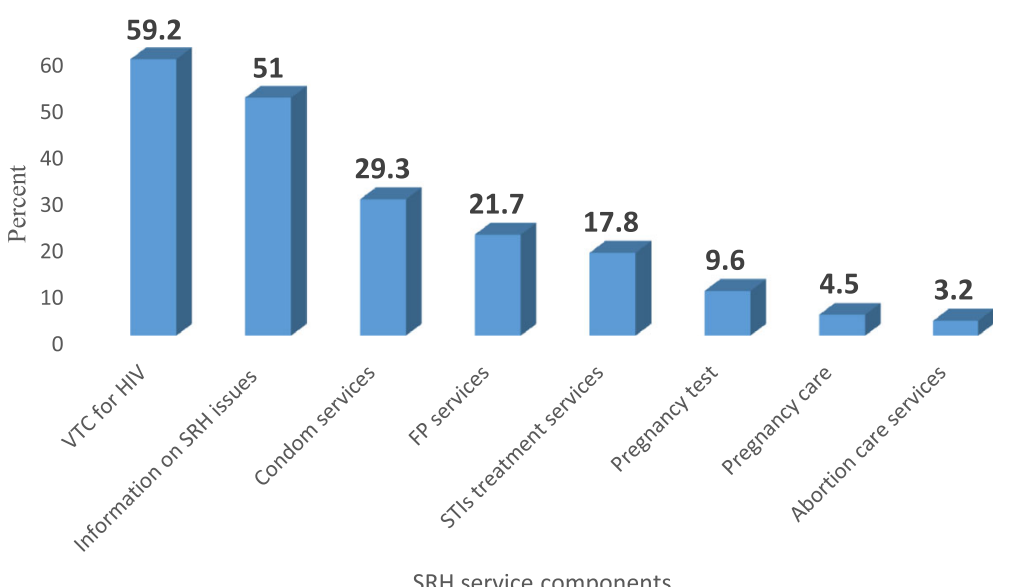

SRH service components

Fig. 2 Components of SRH services utilized by secondary school youths in Nekemte Town, 2016

issues from their school teacher. The odds of SRH service utilization was about 6 times $[\mathrm{AOR}=5.87,95 \% \mathrm{CI}$ [3.38 to 10.19)] higher among respondents who ever had sexual contact than their counterparts. Respondents who had history of perceived STIs symptoms were 2.6 times (AOR 2.61, 95\%CI [1.24 to 5.49]) more likely to utilize the SRH services.

\section{Discussion}

The overall utilization of SRH among school youths was $21.2 \%$ (95\% CI[18.3-24.0]). It is similar with the crosssectional study conducted in Mekele Town and East Gojjam zone [21, 22]. However, this finding was less than findings from Harar Town, Bahir Dar Town and Hadiya zone [12, 15, 23]. The possible reason for the discrepancy might be due to respondent characteristics, socio-demographic backgrounds and time reference used in the definition of SRH service utilization [24].

Around $13.7 \%$ of the students (9.5\% male) were found to be sexually active within the last 12 month. Even though it seems low percentage of respondents, sexual behavior may have been masked because of the sociocultural context, where sexual intercourse out of marriage is taboo.This result was consistent with another study from Mekele and Nepali [22, 25]. But this percentage is lower than studies in Bahir Dar and Hadiya [17, 26]. The difference might be due to socio-cultural background in which early marriage is encouraged in the two areas. In addition, the number of sexually active male students is greater than of female student. This might indicate that male are having sex with out of school females. The mean age at first sexual contact of respondents was 15.14 indicating early initiation of sexual

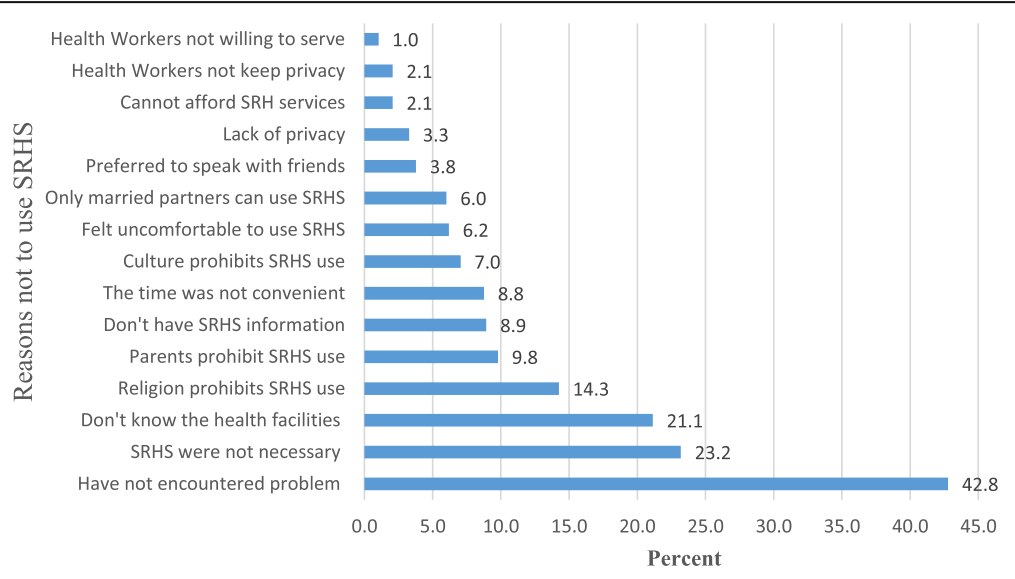

Fig. 3 Reasons not to utilize SRHS by secondary cchool youths in Nekemte Town, 2016 
Table 4 Bivaraite and Multivariate logistic regression analysis of factors associated with SRH services utilization among secondary school students, Nekemte, April 18-22, 2016

\begin{tabular}{|c|c|c|c|c|c|}
\hline \multirow[t]{2}{*}{ Variables } & & \multicolumn{2}{|c|}{ SRH service utilization } & \multirow[t]{2}{*}{ COR $(95 \% \mathrm{Cl})$} & \multirow[t]{2}{*}{ COR $(95 \% \mathrm{Cl})$} \\
\hline & & Yes (\%) & No (\%) & & \\
\hline \multicolumn{6}{|l|}{ Age } \\
\hline $15-19$ & & $132(84.1)$ & 374(92.6) & 1 & 1 \\
\hline $20-24$ & & 25(15.9) & $30(7.4)$ & $2.36(1.34-4.16)^{*}$ & $1.15(0.51-2.57)$ \\
\hline \multicolumn{6}{|l|}{ Marital status } \\
\hline Married & & $11(7.0)$ & $11(2.7)$ & $2.69(1.14-6.34)^{*}$ & $1.9(0.58-6.48)$ \\
\hline Single & & 146(93.0) & 393(97.3) & 1 & 1 \\
\hline \multicolumn{6}{|l|}{ School type } \\
\hline Government & & 139(88.5) & $315(78.0)$ & 1 & 1 \\
\hline Non-government & & 18(11.5) & $89(220)$ & $0.46(0.27-0.79)^{*}$ & $0.56(0.26-1.20)$ \\
\hline \multicolumn{6}{|l|}{ Discussion on SRH } \\
\hline \multirow[t]{2}{*}{ With friends } & Yes & $76(60.3)$ & 239(76.6) & $0.46(0.3-0.72)^{*}$ & $0.73(0.39-1.37)$ \\
\hline & No & $50(39.7)$ & $73(23.4)$ & 1 & 1 \\
\hline \multirow[t]{2}{*}{ With health workers } & Yes & $59(46.8)$ & $75(24.0)$ & $2.78(1.8-4.3)^{*}$ & $3(1.72-5.24)^{* * * *}$ \\
\hline & No & $67(53.2)$ & 237(76.0) & 1 & 1 \\
\hline \multicolumn{6}{|l|}{ Sources of SRH services } \\
\hline \multirow[t]{2}{*}{ School teachers } & Yes & $47(29.9)$ & $209(51.7)$ & $0.4(0.27-0.59)^{*}$ & $0.36(0.21-0.61)^{* * *}$ \\
\hline & No & $110(70.1)$ & 195(48.3) & 1 & 1 \\
\hline \multirow[t]{2}{*}{ History of STIS } & Yes & $33(24.3)$ & $22(6.8)$ & $4.41(2.46-7.91)^{*}$ & $2.61(1.24-5.49)^{* *}$ \\
\hline & No & 103(75.7) & 303(93.2) & 1 & 1 \\
\hline \multirow[t]{2}{*}{ Sexually ever experienced } & Yes & $79(50.3)$ & 48(11.9) & $7.51(4.87-11.6)^{*}$ & $5.87(3.38-10.19)^{* * *}$ \\
\hline & No & 78(49.7) & $356(88.1)$ & 1 & 1 \\
\hline \multicolumn{6}{|l|}{ Attitude for SRH services } \\
\hline Unfavorable attitude & & $62(39.7)$ & 198(49.1) & 1 & 1 \\
\hline Favorable attitude & & $94(60.3)$ & 205(50.9) & $1.46(1.01-2.13)^{*}$ & $1.21(0.69-2.10)$ \\
\hline
\end{tabular}

intercourse. Sixteen (15.8\%) of sexually active respondents had multiple sexual partiner that may pose them for risky sexual behavior and these are important indicators of exposure to risk of pregnancy and STI during adolescence. This finding was in line with the study conducted in Mekele Town [22].

Majority of sexually active respondents $62(61.4 \%)$ had received at least one component of the SRH services in the last twelve months. This finding goes in line with the finding from Hadiya zone [14]. The possible justification of this may be sexually active respondents were more exposed for SRH problems so that they were concerned about their sexual and reproductive healths than sexually inactive respondents.

The commonly utilized SRH service component was voluntary testing and counseling service (59.2\%) which is almost similar with the findings of studies done in Goba Town and Gondar Town [27, 28]. Information and counseling on SRH issues, condom services and STIs services were also commonly recieved by $51.0 \%$, $29.3 \%$ and $17.8 \%$ of the SRH services seekers respectively. This finding somewhat goes in line with the finding in Mekele Town [22]. Family planning service was utilized by 26 . $7 \%$ of the sexually active respondents which was similar to the findig from Nepali $[25,29]$ but less than findings in Gondar Town and Goba Town [27, 28]. The possible explanation for this difference might be due to more implimentation opportunities at the community than at school level and information gap among school youths of the study area as more government and nongovernment facilities are designed and implementing at community level.

The findings of this study indicated that school youths used various health facilities in which government health facilities most frequently cited (50.9\%) followed by NGO health facilities similar to those previous studies conducted in Bahir Dar [17]. The possible explanation for this could be the services in governmental and NGO 
health institutions were given either free of charge or with a minimal payment.

This study also showed that a small proportion (3.8\%) of the participants used traditional health service that goes in line with Bahir Dar and East Gojjam study [17, 21]. Even if this proportion seems insignificant, it needs a special concern because unless it is confirmed by health experts traditional treatments may pose health risks to individuals.

For the successfulness of the YSRH program appropriate and relevant information about SRH should be delivered to youths. In this study, Medias (45.1\%), teachers (41.3\%) and health workers (36.7\%) were found to be the main source of information about SRH services which was in line with the finding from Mekele [22].

The result of this study showed that majority of the respondents had not utilized SRH services diferrent reasons. Absence of SRH problems for a moment and the service was not necessary for the moment were most commonly cited reasons not to use SRH services. Religion, cultural and parent prohibition, inconvenience service hour and lack of privacy at delivery point were also barriers to SRH services utilization. This finding was consistent with the findings of East Gojjam, Bahir Dar and Mtwara Tanzania [17, 21, 30]. This implies that there is a need of tackling the barriers by dealing with the community leaders, religious leaders, families and health service systems.

In this study, discussion with health workers, previous history of perceived STIs symptoms, being ever sexually experienced and exposure to information from school teachers were found to be independent determinants of SRH services utilization among school youths.

This study revealed that discussion of the service with health care workers had a significant association with SRH service utilization. This can be justified by the fact that discussion of services with people allows youths to create more opportunities to exchange information, experiences, and build comprehensive knowledge about SRH. It can also create opportunities to deal with adolescent problems associated with SRH service utilization so that health professionals might be the source of accurate information for youths which help them for appropriate decision making in health services seeking behavior.

School youths who had encountered at least one of STIs symptom were more likely to utilize SRH services than who did not encounter the problem. And also individuals who had ever sexual contact were more likely to utilize SRH services than abstainers. This finding goes in line with study conducted in Hadiya, Nepali and Bahir Dar $[12,15,29]$ This might be explained as youths were more concerned about their health when they encounter SRH problems that triggered them to use SRH services and youths who engaged in sexual intercourse were more vulnerable to SRH problems that might increase the need for SRH services utilization. This implies that youths need an access to a wide range of health information and services as well as health professional support to engage in healthy and safe behavior.

The students who had heard SRH related issues from their school teachers seemed to be $64 \%$ less likely to utilize SRH service than students who had not heard from school teachers in contrary to the fact that school teachers were the main sources of information for SRH. The justification of this finding is not simple and difficult to hypothesize that information leads to less SRH service utilization. In fact school teachers may strictly disseminate information that early sexual initiation can lead to risk of unwanted pregnancy and STIs. Therefore, before formulating hypotheses about information from school teachers, additional studies using qualitative designs are needed to dig out the deeper meaning and to identify type of information delivered by school teachers.

\section{Limitation}

Since this study examines personal and sensitive issues, obtaining honest responses among adolescent students might have been difficult. Therefore this data might have prone to respondent bias. The quantitative study design did not allow for probing into certain areas which needed further qualitative description. Finally, the study was conducted in schools of only one town, which means the findings may not be generalizable to the overall Ethiopian adolescent and youth population, who are socio-economically, linguistically, and ethnically diverse. In addition factors at community (e.g. parental attitude and control over the children) and health system are needed to be included in the future researches.

\section{Conclusion}

This study had showed that low proportion of the school youths visited different health facilities to utilize SRH services in the last 12 months. The most frequently utilized SRH service component was voluntary testing and counseling service followed by information and counseling on SRH issues. Media was the potential source of information on SRH services for school youths followed by teachers and health workers. Discussion with health workers, previous history of perceived STIs symptoms, being ever sexually experienced and exposure to information from school teachers were found to be independent determinants of SRH services utilization among school youths.

\section{Abbreviations}

NGOs: Non-Governmental Organizations; RH: Reproductive Health; SPSS: Statistical Package for the Social Sciences; SRH: Sexual and

Reproductive Health; SRHS: Sexual and Reproductive Health Services 


\section{Acknowledgements}

We would like to pass our thanks to Jimma University with its respective College of Health sciences, Department of Population and Family Health. Our thanks also go to the school teachers who devoted their time from the busy schedule during data collection, all the study participants for giving us their busy time of study and who had took part in the survey, data collection facilitation and supervisions.

\section{Funding}

Sponsored by Jimma University.

\section{Availability of data and materials}

The datasets in which conclusion taken is available in the form of Microsoft Excel. It is available on requesting.

\section{Authors' contributions}

"These authors contributed equally to this work. All authors of this paper have read and approved the final version before submission.

\section{Ethics approval and consent to participate}

Ethical clearance was obtained from Jimma University, Collage of Health Sciences ethical review committee. Then letter of permission was written from the Oromia Regional Health Bureau to Nekemte Town Health and Education Offices. Cooperation letter was taken to each selected School Directors of the randomily selected schools from which the data is to be collected. Verbal informed consent was obtained from the selected individuals after objective of the study was communicated in detail. The respondents were assured that they have the right to be involved or not in the study, and that their noninvolvement will not affect them in any way. Participants were not requested for name or any identifier on the questionnaire.

\section{Consent for publication}

Not applicable.

\section{Competing interests}

The authors declare that they have no competing interests.

\section{Publisher's Note}

Springer Nature remains neutral with regard to jurisdictional claims in published maps and institutional affiliations.

\section{Author details}

'Department of Midwifery, Arba Minch College of Health Sciences, Arba Minch, Ethiopia. ${ }^{2}$ Department of Midwifery, College of Health Sciences and Medicine, Wolaita Sodo University, Wolaita Sodo, Ethiopia. ${ }^{3}$ Department of Population and Family Health, College of public Health and Medical Sciences, Jimma University, Jimma, Ethiopia.

Received: 8 December 2017 Accepted: 28 March 2018 Published online: 17 April 2018

\section{References}

1. United Nations Development of Economic and Social Association, Youth population trends and sustainable development. 2015

2. United Nations Population Fund, Status Report on Adolescents and Young People In Sub-Saharan Africa; Opportunities and Challenges. 2012: 7 Naivasha Road, Sunninghill, Johannesburg, 2157 South Africa.

3. Central Statistical Agency of Ethiopia, Ethiopia Mini Demographic and Health Survey. 2014: Addis Ababa.

4. Siegrid Tautz The Youth to Youth Initiative: an assessment of results in Ethiopia and Kenya. 2011.

5. Population Reference Bureau, The World's Youth. 2013.

6. United Nations, Framework of actions for the follow-up to the Programme of action of the international conference on population and development beyond. 2014

7. United Nations Education Social and Culture Organization, One Year in Review | 2013-2014 Eastern And Southern; The Eastern and Southern Africa (ESA ) Commitment. 2014

8. Abebe M, Tsion A, Netsanet F. Living with parents and risky sexual behaviors among preparatory school students in Jimma zone, south West Ethiopia. African Halth Sci. 2013;13(2):498-506.
9. Bogale A, Seme A. Premarital sexual practices and its predictors among in school youths of shendi town, west Gojjam zone, north western Ethiopia. BIOMED Cent Reprod Heal. 2014;11(1):1-9.

10. Yohannes B, Gelibo T, and T. M, Prevalence and Associated Factors of Sexually Transmitted Infections among Students of Wolaita Sodo University, Southern Ethiopia.. Int J Sci Technol Res, 2013. 2(2): p. 86-94.

11. Gelaye, A.A., KNT, and TM, Magnitude and risk factors of abortion among regular female students in Wolaita Sodo University, Ethiopia BMC Womens Health, 2014. 14(50): p. 1-9.

12. Cherie, N., G. Tura, and N. Teklehaymanot, Reproductive health needs and service utilization among youths in West Badewacho Woreda, Hadiya. 7(April): p. 145-153.

13. Harar Bulletin of Health Sciences Extracts Number 4. Youth-friendly health services utilization and factors in Harar, Ethiopia Aboma Motuma. In: 4; January 2012.

14. Bilal, S.M., et al., Sexual \& Reproductive Healthcare Utilization of Sexual and Reproductive Health Services in Ethiopia-Does it affect sexual activity among high school students? Sexual \& Reproductive Healthcare. 6(1): p. 14-18.

15. Abebe, M. and W. Awoke, Utilization of Youth Reproductive Health Services and Associated Factors among High School Students in Bahir Dar, Amhara Regional State. (May): p. 69-75.

16. International, C.S.A.E.a.I., Ethiopia Demographic and Health Survey 2011. 2012, Central statistical agency and ICF international: Addis Ababa, Ethiopia and Calverton, Maryland, USA. p. 450.

17. Abebe M, Awoke W. Utilization of youth reproductive health services and associated factors among high school students in Bahir Dar, Amhara regional state. Open J Epidemiol. 2014;4:69-75.

18. Hynes, M., Et al., Reproductive Health Assessment Toolkit for ConflictAffected Women. 2007: Atlanta, GA.

19. J., C., Illustrative Questionnaire for Interview Surveys with Young People.

20. Control, C.O.D. Reproductive health assessment questionnaire for conflictaffected WomenCDC. 2011

21. Abajobir AA, Seme A. Reproductive health knowledge and services utilization among rural adolescents in east Gojjam zone, Ethiopia : a community-based cross-sectional study. BMC Health Serv Res. 2014;14(1):1-11.

22. Bilal SM, et al. Sexual \& Reproductive Healthcare Utilization of sexual and reproductive health Services in Ethiopia - does it affect sexual activity among high school students ? Sex Reprod Healthc Elsevier BV. 2015;6(1):14-8.

23. Malarcher S, Social determinants of sexual and reproductive health. 2010: Geneva Swizerland:

24. Motuma A, Youth-friendly Health Services Utilization and Factors in Harar, Ethiopia. Harar Bull Heal Sci. 2012 4(5.).

25. Bam K, et al. Perceived sexual and reproductive health needs and service utilization among higher secondary school students in urban Nepal. Am J Public Heal Res. 2015;3(2):36-45.

26. Cherie N, Tura G, Teklehaymanot N. Reproductive health needs and service utilization among youths in west Badewacho Woreda, Hadiya zone, Ethiopia. J Public Heal Epidemiol. 2015:7(4):145-53.

27. Feleke SA, et al. Reproductive health service utilization and associated factors among adolescents ( 15 - 19 years old ) in Gondar town, northwest. BMC Health Serv Res. 2013;13(1):1.

28. Gebreselassie B, et al., Assessment of Reproductive Health Service Utilization and Associated Factors Among Adolescents ( 15-19 Years Old ) in Goba Town, Southeast Ethiopia. 2015. 3(4): p. 203-212.

29. Bam, K., et al., Perceived Sexual and Reproductive Health Needs and Service Utilization among Higher Secondary School Students in Urban Nepal. 3(2): p. $36-45$.

30. Mbeba RM, et al. Barriers to sexual reproductive health services and rights among young people in Mtwara district, Tanzania : a qualitative study. Pan Afr Med J. 2012;13(1):1-6. 